Case Study

\title{
Effect of joint mobilization using KEOMT and PNF on a patient with CLBP and a lumbar transitional vertebra: a case study
}

\author{
Si-Eun Park, PT, MS ${ }^{1)}$, JoONG-SAn Wang, PT, MS ${ }^{2 *}$ \\ 1) Department of Physical Therapy, Yongin University, Republic of Korea \\ 2) Department of Physical Therapy, Yeoju Institute of Technology: 338 Sejong-ro, Yeoju-si, \\ Gyeonggi-do, Republic of Korea
}

\begin{abstract}
Purpose] The purpose of this case study was to identify the effects of joint mobilization using Kaltenborn-Evjenth orthopedic manual therapy (KEOMT) and proprioceptive neuromuscular facilitation (PNF) techniques on a patient with chronic low back pain (CLBP) and a lumbar transitional vertebra. [Methods] The intervention methods were joint mobilization using KEOMT and PNF techniques. The program consisted of 40-min sessions 3 days a week for 4 weeks. The spinal motion (thoracic and lumbar vertebrae), pain, and thickness of the multifidus were measured. [Results] The angle of spinal curvature increased, and the range of motions (ROMs) flexion and extension increased in the thoracic and lumbar vertebrae. The pain score as measured on a visual analogue scale (VAS) and the Oswestry disability index (ODI) score decreased. The thickness of the multifidus (L4) increased on the left and right sides. [Conclusion] These results suggest that joint mobilization using KEOMT and PNF techniques had a positive effect on the spinal motion, pain, and thickness of the multifidus of a patient with chronic low back pain and a lumbar transitional vertebra.

Key words: Lumbar transitional vertebra, Joint mobilization, Proprioceptive neuromuscular facilitation
\end{abstract}

(This article was submitted Dec. 11, 2014, and was accepted Jan. 31, 2015)

\section{INTRODUCTION}

Chronic low back pain (CLBP) refers to chronic pain around the lumbar vertebra sustained for over three months without serious pathological characteristics, regardless of the existence of sciatalgia ${ }^{1)}$. CLBP causes pain and changes in the muscles, as well as decreases in contractile force and muscle activity. It also affects vertebral movement ${ }^{2-4)}$. Studies of therapeutic approaches to CLBP pain reduction, muscular strength improvement, and spinal movement enhancement have investigated the effects of myofacial release, osteopathy, massage, lumbar stabilization exercises, and proprioceptive neuromuscular facilitation $(\mathrm{PNF})^{5-7)}$.

Among these therapeutic approaches, joint mobilization using PNF has a positive effect on pain, muscle strength, and range of motion $(\mathrm{ROM})^{8,9)}$. Joint mobilization is an effective method for improving ROM and body alignment. It is applied as a passive movement by therapists ${ }^{10,11)}$. In particular, Kaltenborn-Evjenth orthopedic manual therapy (KEOMT) is an effective treatment for improving ROM and pain. KEOMT is a safe and well-established procedure that

*Corresponding author. Joong-San Wang (E-mail: king9655@empas.com)

(C2015 The Society of Physical Therapy Science. Published by IPEC Inc. This is an open-access article distributed under the terms of the Creative Commons Attribution Non-Commercial No Derivatives (by-ncnd) License $<$ http://creativecommons.org/licenses/by-nc-nd/3.0/> . slowly utilizes the convex-concave rule (traction or gliding on the treatment side) ${ }^{10,12)}$.

The PNF technique is an effective therapy for relieving lumbar back pain. Hindle et al. reported PNF is effective at improving ROM and muscular strength ${ }^{13)}$. Kim et al. reported that lumbar stabilization therapy using PNF for CLBP significantly improved the thicknesses of the external oblique and multifidus muscles, and the functional level ${ }^{8)}$. In addition, PNF has been used to improve the muscular strength of athletes ${ }^{14}$.

This case study was a single patient with CLBP and a lumbar transitional vertebra who has six lumbar vertebrae (not five). A lumbar transitional vertebra is defined as a congenital malformation that appears as a deformation of the fifth lumbar (L5) or first sacrum (S1) vertebra ${ }^{15}$. Vergauwen reported that lumbar transitional vertebrae patients more commonly experience disc protrusion, degeneration, and spinal stenosis than patients without lumbar transitional vertebrae ${ }^{16)}$

Few studies have investigated CLBP with a lumbar transitional vertebra. Therefore, the purpose of this study was to identify the effects of joint mobilization using KEOMT and PNF on a patient with CLBP and a lumbar transitional vertebra. We evaluated spinal motion, pain, and the thickness of the multifidus.

\section{SUBJECT AND METHODS}

The subject was selected from among the patients of Sa- 


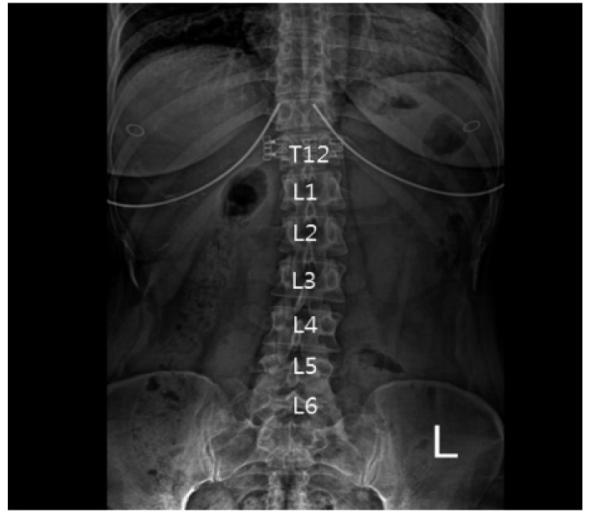

Fig. 1. Lumbar transitional vertebrae

rang Hospital (Yongin, South Korea). This study conformed to the ethical principles of the Declaration of Helsinki. The subject agreed to participate in the study after receiving explanations regarding the purpose and procedures of the experiment, and signed an informed consent statement before participation. The protocol for this study was approved by the local ethics committee of the Namseoul University of Cheonan.

The subject was diagnosed as having CLBP and a lumbar transitional vertebra. Computer tomography (CT) showed six lumbar vertebrae, which is one more lumbar vertebra than a normal person (Fig. 1). This indicates the first sacrum is not completely integrated. The subject was aged 29 , and had a weight of $67 \mathrm{~kg}$, a height of $158 \mathrm{~cm}$, and a BMI of 26.90 .

The subject was a nulliparous married woman. The subject had been working as a nurse for ten years. The initial symptom developed about two years earlier, and at the time of the study the subject was not receiving any medical or physical therapy. The major complaint of the subject was a numb feeling, especially in the hind part of the left leg. She also complained of a stinging pain during daily activities, such as lifting, lumbar twist, and flexion.

The program consisted of a 40-min session, 3 days a week for 4 weeks (October 1-31, 2014), during which joint mobilization was performed using KEOMT and PNF techniques.

Joint mobilization using KEOMT lasted $20 \mathrm{~min}$, and it included lumbar segmental traction and lumbar segmental mobilization (flexion, extension) in a side-lying position. The gliding therapy applied was grade $\mathrm{III}^{10,12)}$. It was performed by a therapist who had completed a KEOMT Spine advance course.

The PNF therapy lasted $20 \mathrm{~min}$. The PNF exercise included shoulder flexion, abduction, and external rotation in a supine position, and dynamic reversal of the antagonist was performed ${ }^{17)}$, which indirectly exercised the abdominal muscle through irradiation of the shoulder muscle. It was performed by a therapist who had completed the PNF level I, II courses.

The subject was assessed for spinal motion, low back pain, and thickness of the multifidus. Spinal motion was assessed using a spinal mouse (Idiag, Swiss), which measures the spinal curvature, flexion, and extension (thoracic and
Table 1. Change of thoracic and lumbar movement

\begin{tabular}{lcccccc}
\hline \multirow{2}{*}{ Variable } & \multicolumn{2}{c}{ Curvature $\left(^{\circ}\right)$} & \multicolumn{2}{c}{ Flexion $\left(^{\circ}\right)$} & \multicolumn{2}{c}{ Extension $\left({ }^{\circ}\right)$} \\
\cline { 2 - 7 } & pre & post & pre & post & pre & post \\
\hline Thoracic & 26 & 32 & 14 & 20 & 1 & 4 \\
Lumbar & 12 & 20 & 33 & 47 & 2 & 7 \\
\hline
\end{tabular}

Table 2. Change of VAS and ODI

\begin{tabular}{ccccc}
\hline \multirow{2}{*}{ Variable } & \multicolumn{2}{c}{ VAS (Score) } & \multicolumn{2}{c}{ ODI (\%) } \\
\cline { 2 - 5 } & pre & post & pre & post \\
\hline 7.5 & 3 & 48.88 & 24.44 \\
\hline
\end{tabular}

Table 3. Change of multifidus thickness

\begin{tabular}{lcc}
\hline Variable & Pre & Post \\
\hline \multirow{2}{*}{ multifidus $\left(\mathrm{mm}^{2}\right)$} & L $: 572.09$ & L : 662.09 \\
& R : 479.84 & R : 530.90 \\
\hline
\end{tabular}

L: left; R: right

lumbar vertebrae). Low back pain was assessed using a visual analogue scale (VAS) and the Oswestry disability index (ODI). The VAS assesses subjective pain through a which has a possible range of 0 to 10 . This measurement has a high reliability $(\mathrm{ICC}=0.9)^{18)}$. The ODI assesses low back pain, and has a possible range of 0 to $100 \%$. It is composed of ten items, including pain severity, self-management, lifting, sitting, standing, sleeping, etc. This study used the Korean version $\mathrm{ODI}^{19}$ ). Higher VAS and ODI scores indicate more severe pain. The thickness of the multifidus was measured using CT (General Electric, Korea). The multifidus muscles of the fourth lumbar vertebra (L4) ${ }^{20)}$ was scanned by a radiological thechnician at Sarang Hospital.

\section{RESULTS}

The spinal curvature, flexion, and extension of thoracic and lumbar vertebrae were measured. In the thoracic vertebra, the angle of spinal curvature increased from $26^{\circ}$ to $32^{\circ}$ after the intervention. The ROM of flexion increased from $14^{\circ}$ to $20^{\circ}$, and the ROM of extension increased from $1^{\circ}$ to $4^{\circ}$. In the lumbar vertebra, the angle of spinal curvature increased from $12^{\circ}$ to $20^{\circ}$. The ROM in flexion increased from $33^{\circ}$ to $47^{\circ}$, and the ROM of extension increased from $2^{\circ}$ to $7^{\circ}$ (Table 1 ).

The VAS score decreased from 7.5 to 3 . The subject mentioned she was less uncomfortable in daily life, e.g. during face washing, dishwashing, hair washing, etc. The ODI percentage score decreased from 48.88 to 24.44 (Table 2).

The thickness of the multifidus was measured at the fourth lumbar vertebra (left and right). The left multifidus increased from 572.09 to $662.09 \mathrm{~mm}^{2}$, and the right multifidus increased from 479.84 to $530.90 \mathrm{~mm}^{2}$ (Table 3). Figures 2 and 3 show the multifidus thickness on a CT. 


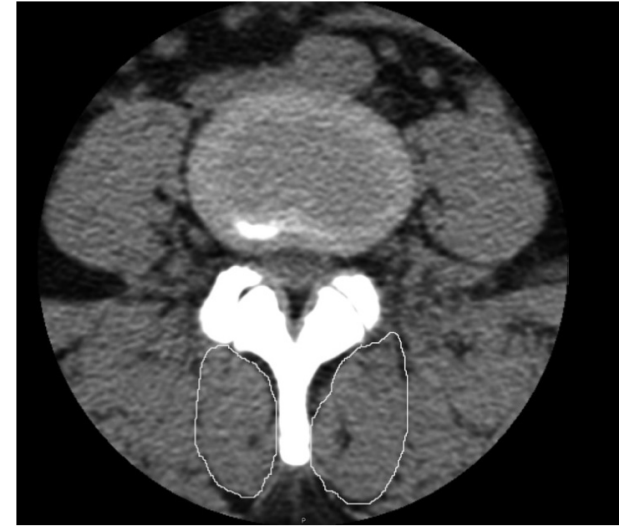

Fig. 2. Multifidus thickness on a CT (Pre)

\section{DISCUSSION}

This study was a case study of a single patient with CLBP and a lumbar transitional vertebra. The purpose of this study was to identify the effects of joint mobilization using KEOMT and PNF techniques in a patient with CLBP and a lumbar transitional vertebra. The spinal motion, pain, and thickness of the multifidus were evaluated and compared between pre- and post-assessment.

The subject was a 29 year-old nurse. Nurses have a high risk of musculoskeletal disorders. Florentino et al. reported that most nurses possess at least one musculoskeletal disorder, among which low back pain is the most frequent $(60.9 \%)^{21)}$.

After the intervention, the angle of spinal curvature increased, and the ROMs of flexion and extension of the thoracic and lumbar vertebrae also increased, indication that joint mobilization using KEOMT and PNF had a positive effect on spinal motion. Ko et al. reported that CLBP patients in a thoracic joint mobilization group showed greater improvements in spinal motion and pain reduction than a William exercise group ${ }^{22}$. Our present results were similar, suggesting that joint mobilization has a positive effect on spinal motion.

Pain was assessed using the VAS and ODI. After the intervention, the VAS score decreased from 7.5 to 3, and the ODI score decreased from $48.88 \%$ to $24.44 \%$. Orthopedic manual therapy has positive effects on the spinal function of CLBP patients ${ }^{6}$, especially items of self-management, such as bathing, dressing, and sleeping. Passive joint accessory mobilization was used to reduce pain. Villafañe et al. reported pain reduction after joint mobilization using KEOMT was performed for osteoarthritic elderly people ${ }^{23)}$, and López et al. reported joint postero-anterior mobilization had an effect on the pain and ROM of CLBP patients ${ }^{9)}$.

Lee reported a PNF group demonstrated greater pain reduction and increased muscle activity than a ball training group, and Jung reported PNF reduced the pain of CLBP patients $^{24,25)}$. In addition, PNF was effective at increasing muscular endurance and spinal mobility ${ }^{26)}$. Therefore, the results of previous studies agree with those of the present study.

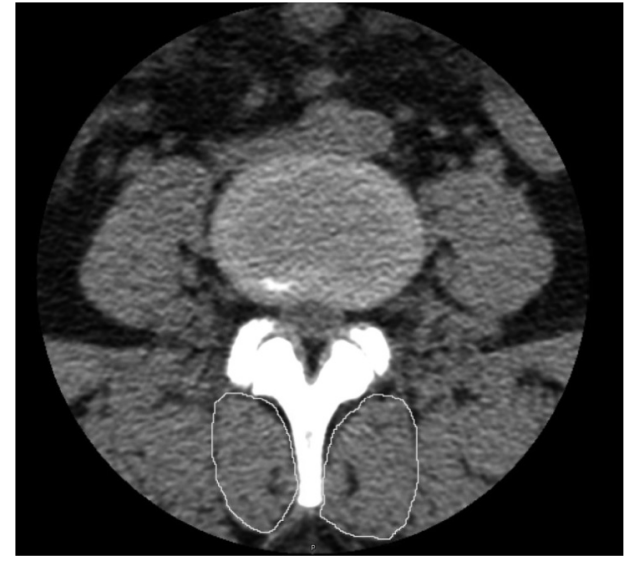

Fig. 3. Multifidus thickness on a CT (Post)

Spinal alignment and muscle strength are important for spinal stability ${ }^{27)}$. The spinal muscle contracts prior to motion and controls the movement ${ }^{28)}$. In particular, the multifidus muscle is important for lumbar stabilization. The superficial multifidus plays a role in spinal direction control, and the deep multifidus plays a role in intervertebral movement control ${ }^{29)}$. This study measured the thickness of the multifidus on both sides. After the intervention, the left multifidus increased from 572.09 to $662.09 \mathrm{~mm}^{2}$, and the right multifidus was increased from 479.84 to $530.90 \mathrm{~mm}^{2}$. Kim et al. reported a PNF group showed greater increases in the thicknesses of the multifidus and external oblique muscles than a general physiotherapy group and a lumbar stabilization group ${ }^{8}$. In addition, a resistance exercise using PNF not only reinforced muscular strength causing maximal muscular contraction, but it also stabilized the body position $^{30)}$. These results indicate PNF has a positive effect on the thickness of the multifidus.

According to our present results, joint mobilization using KEOMT and PNF had a positive effect on the spinal motion, pain, and thickness of the multifidus of a patient with CLBP and a lumbar transitional vertebra. This study was a single subject case study, but it is meaningful in that it presented spinal motion, pain, and muscle activity in a patient with a lumbar transitional vertebra. A larger number of patients will need to be studied in the future.

\section{REFERENCES}

1) Nielens H, Zundert JV, Mairiaux P, et al: Chronic low back pain. KCE report, 2006, 48: 5-67.

2) Vlaeyen JW, Kole-Snijders AM, Boeren RG, et al.: Fear of movement/(re) injury in chronic low back pain and its relation to behavioral performance. Pain, 1995, 62: 363-372. [Medline] [CrossRef]

3) Wallwork TL, Stanton WR, Freke M, et al.: The effect of chronic low back pain on size and contraction of the lumbar multifidus muscle. Man Ther, 2009, 14: 496-500. [Medline] [CrossRef]

4) Dickey JP, Pierrynowski MR, Bednar DA, et al.: Relationship between pain and vertebral motion in chronic low-back pain subjects. Clin Biomech (Bristol, Avon), 2002, 17: 345-352. [Medline] [CrossRef]

5) Ajimsha MS, Daniel B, Chithra S: Effectiveness of myofascial release in the management of chronic low back pain in nursing professionals. $J$ Bodyw Mov Ther, 2014, 18: 273-281. [Medline] [CrossRef]

6) Licciardone JC, Kearns CM, Minotti DE: Outcomes of osteopathic manual treatment for chronic low back pain according to baseline pain severity: 
results from the OSTEOPATHIC Trial. Man Ther, 2013, 18: 533-540. [Medline] [CrossRef]

7) Sritoomma N, Moyle W, Cooke M, et al.: The effectiveness of Swedish massage with aromatic ginger oil in treating chronic low back pain in older adults: a randomized controlled trial. Complement Ther Med, 2014, 22 26-33. [Medline] [CrossRef]

8) Kim GD, Lee YJ, Choi WS, et al.: Effect of lumbar stabilization exercise using PNF technique on thickness of lumbar deep muscle and functional activity in chronic low back pain patients. The Korea Contents Association, 2012, 12(3): 233-243.

9) López CC, Barra ME, Villar E, et al.: Effectiveness of the posteroanterior mobilization in the lumbar raquis with the Kaltenborn wedge in chronic low back pain patients. Fisioterapia, 2007, 29: 261-269.

10) Kaltenborn FM, Evjenth O, Kaltenborn TB, et al.: The Spine: Basic Evaluation and Mobilization Technique. Olaf Norlis Bokhandel, 1993.

11) Neumann DA: Kinesiology of the musculoskeletal system: Foundations for rehabilitation. St. Louis: Mosby, 2010

12) Herrero $\mathrm{P}$, Tricas J, Lucha $\mathrm{O}$, et al.: Indirect influence of specific Kaltenborn glide mobilizations of the carpal joint on a subject with neurological impairments. J Bodyw Mov Ther, 2007, 11: 275-284. [CrossRef]

13) Hindle KB, Whitcomb TJ, Briggs WO, et al.: Proprioceptive Neuromuscular Facilitation (PNF): its mechanisms and effects on range of motion and muscular function. J Hum Kinet, 2012, 31: 105-113. [Medline] [CrossRef

14) Kofotolis N, Vrabas IS, Vamvakoudis E, et al.: Proprioceptive neuromuscular facilitation training induced alterations in muscle fibre type and cross sectional area. Br J Sports Med, 2005, 39: e11. [Medline] [CrossRef]

15) Kim YH, Yoon KS: Far-out stenosis by lumbosacral transitional vertebrae. J Korean Orthop Assoc, 2011, 46: 438-442. [CrossRef]

16) Vergauwen S, Parizel PM, van Breusegem L, et al.: Distribution and incidence of degenerative spine changes in patients with a lumbo-sacral transitional vertebra. Eur Spine J, 1997, 6: 168-172. [Medline] [CrossRef]

17) Surburg PR, Schrader JW: Proprioceptive neuromuscular facilitation techniques in sports medicine: a reassessment. J Athl Train, 1997, 32: 34-39. [Medline]

18) Polly EB, Wendy S, John G: Reliability of the visual analogue scale for measurement of acute pain. Acad Emerg Med, 2001, 8 .
19) Fairbank JC, Pynsent PB: The oswestry disability index. Spine, 2000, 25 2940-2952, discussion 2952. [Medline] [CrossRef]

20) Kim JW, Lee DY: The effect of resistive and stability exercises for lumbar muscles on the strength, cross-sectional area and balance. J Sport Leis Stud, 2010, 39: 737-745

21) Florentino S, Mafalda SU, Antonio SU: Hospital nurses tasks and workrelated musculoskeletal disorders symptom. Work, 2014.

22) Ko TS, Jung HB, Kim JA: The effects of thoracic mobilization on pain, disability index and spinal mobility in chronic low back pain patients. J Spec Educ Rehabil Sci, 2009, 48: 115-137.

23) Villafañe JH, Silva GB, Diaz-Parreño SA, et al.: Hypoalgesic and motor effects of kaltenborn mobilization on elderly patients with secondary thumb carpometacarpal osteoarthritis: a randomized controlled trial. J Manipulative Physiol Ther, 2011, 34: 547-556. [Medline] [CrossRef]

24) Lee CW, Hwangbo K, Lee IS: The effects of combination patterns of proprioceptive neuromuscular facilitation and ball exercise on pain and muscle activity of chronic low back pain patients. J Phys Ther Sci, 2014, 26: 93-96. [Medline] [CrossRef]

25) Jung YJ: The effect of low back pain on the total pattens of proprioceptive neuromuscular facilitation. Department of Physical Therapy Graduate School of Rehabilitation Science, Daegu University

26) Kofotolis N, Kellis E: Effects of two 4-week proprioceptive neuromuscular facilitation programs on muscle endurance, flexibility, and functional performance in women with chronic low back pain. Phys Ther, 2006, 86: 1001-1012. [Medline

27) Panjabi MM: Clinical spinal instability and low back pain. J Electromyogr Kinesiol, 2003, 13: 371-379. [Medline] [CrossRef]

28) Hodges PW, Richardson CA: Delayed postural contraction of transversu abdominis in low back pain associated with movement of the lower limb. J Spinal Disord, 1998, 11: 46-56. [Medline] [CrossRef]

29) MacDonald DA, Moseley GL, Hodges PW: The lumbar multifidus: does the evidence support clinical beliefs? Man Ther, 2006, 11: 254-263. [Medline] [CrossRef]

30) Bae SS, Kim SS, Kim SM, et al.: Treatment approach of instable scapula by proprioceptive neuromuscular facilitation. Korea Proprioceptive Neuromuscular Facilitation Association, 2006, 4: 1-7. 